\title{
Pemberitaan Kasus PT PLN (Persero) di Media Siber dan Penerapan Kode Etik Jurnalistik (Analisis Framing Pemberitaan Blackout Listrik 4 Agustus 2019 di Okezone.Com)
}

\author{
Lavenia, Lusia Savitri Setyo Utami \\ Lavenia.915160011@stu.untar.ac.id,Lusias@fikom.untar.ac.id
}

Fakultas Ilmu Komunikasi Universitas Tarumanagara

\begin{abstract}
The power blackout on 4th August 2019 in Banten, Jakarta, West Java, few areas of Central Java caused lots of impacts to citizens. This case is directly related to the public interest, so that the majority of mass media including cyber media reported related information. The purpose of this study is to describe how Okezone.com constructs controversial facts or issues to frame a story into news and to discuss how to apply the Journalistic Code of Ethics (KEJ) in framing the news. The theory used is news as media content as well as online media and journalism. This research is approaching qualitative descriptive with Zhongdang Pan and Gerald M. Kosicki framing model analysis method, the author then examines the application of KEJ clause 1 to 4 in the framing data of the related news. The results showed that Okezone.com framed the coverage of the August 4th, 2019 power blackout using the principle of covering both sides. Okezone.com packed controversial issues related to the point of view that cornered and lended negative public opinion to PLN. Then, Okezone.com was still quite good in applying KEJ clause 1 to 4, because only the rules of clause 2 are indicated to be ignored in the reporting of electricity blackout on August 4th, 2019.
\end{abstract}

Keywords: Framing Analysis, Power Blackout on 4th August 2019, Journalistic Code of Ethics, Cyber Media

\begin{abstract}
Abstrak:
Peristiwa blackout listrik pada 4 Agustus 2019 di daerah Banten, Jakarta, Jawa Barat, hingga sebagian Jawa Tengah, menimbulkan banyak dampak yang dirasakan oleh warga. Kasus ini berkaitan langsung dengan kepentingan publik, sehingga sebagian besar media massa termasuk media siber memberitakan informasi terkait. Tujuan dari penelitian ini adalah untuk mendeskripsikan bagaimana Okezone.com mengkonstruksikan fakta atau isu yang kontroversial untuk membingkai suatu peristiwa menjadi berita serta untuk menggambarkan bagaimana aplikasi Kode Etik Jurnalistik (KEJ) dalam pembingkaian beritanya. Teori yang digunakan adalah berita sebagai konten media serta media dan jurnalistik online. Pendekatan dalam penelitian ini adalah deskriptif kualitatif dengan metode analisis framing model Zhongdang Pan dan Gerald M. Kosicki, lalu penulis mengkaji penerapan KEJ pasal 1 sampai dengan pasal 4 dalam data kerangka framing pemberitaan terkait. Hasil penelitian menunjukkan bahwa Okezone.com membingkai pemberitaan mengenai blackout listrik 4 Agustus 2019 dengan menerapkan prinsip cover both side. Okezone.com mengemas isu-isu kontroversial terkait dengan menonjolkan sudut pandang yang cenderung menyudutkan dan berpotensi menggiring opini publik negatif terhadap pihak PLN. Kemudian, Okezone.com masih cukup baik dalam menerapkan KEJ pasal 1 hingga pasal 4, karena hanya kaidah pasal 2 yang beberapa terindikasi diabaikan dalam pemberitaan blackout listrik 4 Agustus 2019.
\end{abstract}

Kata Kunci: Analisis Framing, Blackout Listrik 4 Agustus 2019, Kode Etik Jurnalistik, Media Siber 


\section{Pendahuluan}

Ketergantungan masyarakat terhadap listrik dalam melakukan berbagai aktivitas sangatlah besar. Peristiwa mati listrik total atau blackout di daerah Banten, Jakarta, Jawa Barat dan sebagian Jawa Tengah terjadi pada tanggal 4 Agustus 2019 tanpa pemberitahuan sebelumnya kepada publik. Pemadaman listrik yang berlangsung cukup lama lantas menimbulkan banyak dampak yang dirasakan oleh warga termasuk mengakibatkan kegiatan pelayanan publik di Jakarta hampir lumpuh seperti MRT, Commuter Line, pelayanan pintu tol, dan ATM (Hasan, 2019). Saat ini berita menjadi salah satu kebutuhan bagi setiap orang untuk mendapatkan informasi mengenai suatu peristiwa atau isu. Peristiwa blackout listrik 4 Agustus 2019 berkaitan langsung dengan kepentingan publik. Maka khalayak perlu mengetahui informasi terkait berdasarkan kebenaran melalui konten berita yang jurnalis siarkan di media massa.

Pengetahuan, pemahaman, dan reaksi publik terhadap sebuah peristiwa sangat bergantung pada pembingkaian berita yang disampaikan oleh jurnalis. Scheufele (1999) dalam Musman dan Mulyadi (2017:139) menjelaskan bahwa dalam memberitakan suatu peristiwa kepada khalayak, jurnalis telah memilih dan memilah bagian dari realitas dan menjadikannya bagian yang penting dari sebuah teks berita atau disebut framing berita. Teknik tersebut dipakai jurnalis untuk melahirkan wacana yang akan ditangkap oleh khalayak. Kemudian, Cangara (2011) dalam Kusumadewi dan Rusdi menjelaskan bahwa media massa tidak sekadar memberitakan mengenai sebuah kejadian atau peristiwa (news event), tetapi ia memiliki tanggung jawab untuk menggiring orang melalui agenda-agenda yang bisa membuka pikiran (2016).

Kehadiran media siber di era new media dimanfaatkan oleh setiap orang untuk mengakses berita secara cepat dan mudah melalui koneksi jaringan internet. Sehingga semakin cepat media tersebut menyalurkan informasi maka semakin cepat reaksi masyarakat terhadap sebuah peristiwa. Salah satu media siber yang telah berstatus terverifikasi administrasi dan faktual oleh Dewan Pers adalah Okezone.com (Dewan Pers, 2008). Dalam menaati Undang-Undang Republik Indonesia Nomor 40 Tahun 1999 tentang pers, media siber tersebut tentu harus menerapkan kode etik jurnalistik dalam menyajikan setiap berita demi menjamin dan memenuhi hak publik untuk mendapatkan informasi yang benar.

Permasalahan pada penelitian ini adalah bagaimana Okezone.com melakukan framing berita tentang blackout listrik 4 Agustus 2019 dan bagaimana Okezone.com menerapkan kode etik jurnalistik pada pemberitaan tersebut. Maka tujuan dari penelitian ini adalah untuk mendeskripsikan pembingkaian atau framing yang dilakukan oleh Okezone.com mengenai pemberitaan blackout listrik 4 Agustus 2019 dan untuk mendeskripsikan penerapan kaidah kode etik jurnalistik pada pemberitaan Okezone.com tersebut.

Dalam penelitian ini penulis menggunakan teori berita sebagai konten media serta media dan jurnalistik online dalam perspektif pembingkaian berita mengenai suatu peristiwa. Kemudian, teori pendukung penelitian ini mencakup komunikasi massa, media massa, media baru, dan analisis framing model Zhongdang Pan dan Gerald M. Kosicki. Selain itu, penelitian ini menggunakan kaidah-kaidah dalam kode etik jurnalistik khususnya pasal 1 sampai dengan pasal 4 yang dikeluarkan oleh Dewan Pers. 
Lavenia, Lusia Savitri Setyo Utami: Pemberitaan Kasus PT PLN (Persero) di Media Siber dan Penerapan Kode Etik Jurnalistik (Analisis Framing Pemberitaan Blackout Listrik 4 Agustus 2019 di Okezone.Com)

Berita adalah laporan tercepat mengenai fakta atau ide terbaru dari suatu peristiwa, menarik dan atau penting bagi sebagian besar khalayak, dan disampaikan melalui media berkala seperti surat kabar, radio, televisi, atau media online (Sumadiria, 2011). Tidak semua peristiwa layak untuk dilaporkan (diberitakan) kepada khalayak, melainkan hanya peristiwa yang memenuhi kriteria nilai berita atau disebut juga nilai jurnalistik meliputi impact (berdampak), proximity (kedekatan geografis dan emosi), timeliness (aktual), prominence (ketokohan), novelty (kebaruan), dan konflik (Romli, 2018).

Kemudian, media online disebut juga media siber merupakan media yang tersaji secara online di situs web melalui jaringan internet (Romli, 2018). Akses jaringannya yang cepat, murah, dan mudah mampu membuat publik menjadi bergantung pada media online. Media ini membantu masyarakat untuk memenuhi berbagai kebutuhan mereka (Muhtadi, 2016). Sejalan dengan adanya media online, jurnalisme online pun hadir dan berkembang pesat di Indonesia.

Jurnalisme online adalah proses penyampaian informasi atau berita yang menggunakan media internet (Musman dan Mulyadi, 2017). Informasi yang tersaji dalam media online bisa diakses kapan saja dan di mana pun, di seluruh dunia, dengan menggunakan komputer dan perangkat lain yang memiliki koneksi internet (Romli, 2018). Selain itu, jurnalisme online memampukan jurnalis untuk terus-menerus memperbarui (update) informasi yang mereka tampilkan di media siber seiring dengan temuan-temuan fakta atau ide baru di lapangan. Munculnya media dan jurnalisme online membuat arus informasi yang berlangsung menjadi makin personal, karena tiap orang mempunyai kebebasan untuk memilih informasi yang mereka butuhkan (Romli, 2016).

\section{Metode Penelitian}

Dalam penelitian ini penulis menggunakan pendekatan deskriptif kualitatif dengan metode analisis framing model Zhongdang Pan dan Gerald M. Kosicki. Bungin (2010) mendefinisikan analisis framing sebagai teknik analisis data dengan melihat dan menemukan bingkai atau kemasan media yakni perspektif yang digunakan jurnalis dalam meliput dan menuliskan berita.

Zhongdang Pan dan Gerald M. Kosicki dalam Eriyanto (2011:294) mengoperasionalisasikan perangkat framing berupa empat dimensi struktural teks berita, yaitu sintaksis, skrip, tematik dan retoris. Struktur sintaksis berkaitan dengan bagaimana jurnalis menyusun peristiwa. Struktur sintaksis ini dapat diamati dari bagian berita seperti headline yang dipilih, lead yang dipakai, latar informasi yang ditampilkan, kutipan yang diambil, sumber, pernyataan hingga penutup. Lalu, struktur skrip berhubungan dengan bagaimana jurnalis mengisahkan fakta ke dalam bentuk berita. Struktur ini dapat diamati untuk mengetahui strategi cara bercerita yang dipakai jurnalis dalam mengemas peristiwa ke dalam naskah berita. Sementara itu, struktur tematik berkaitan dengan bagaimana jurnalis mengungkapkan pandangannya atas peristiwa ke dalam proposisi, kalimat atau hubungan antarkalimat yang membentuk teks berita secara keseluruhan. Kemudian, struktur retoris berhubungan dengan bagaimana jurnalis menekankan makna tertentu ke dalam berita. Struktur ini dapat diamati dengan melihat bagaimana pilihan kata, idiom, grafik, dan gambar yang dipakai oleh jurnalis untuk mendukung tulisan dan menekankan arti tertentu kepada pembaca. 
Bungin dalam bukunya menyatakan "objek dan informan penelitian kualitatif adalah menjelaskan objek penelitian yang fokus dan lokus penelitian, yaitu apa yang menjadi sasaran. Sedangkan informan penelitian adalah subjek yang memahami informasi objek penelitian sebagai pelaku maupun orang lain yang memahami objek penelitian" (2010:76). Dalam penelitian ini, yang menjadi objek penelitian adalah pemberitaan tentang peristiwa blackout listrik 4 Agustus 2019. Dalam rentang waktu 4 Agustus 2019 hingga 31 Agustus 2019 terdapat 42 berita terkait yang disajikan di Okezone.com. Lalu, penulis memilih untuk mengamati dan menganalisis 5 artikel untuk mengetahui bagaimana pembingkaian berita yang dilakukan oleh Okezone.com. Sementara untuk kriteria pemilihan beritanya sendiri adalah berita paling populer atau kontroversial dan paling banyak dibagikan serta yang berkaitan dengan penyebab, upaya pemulihan, tanggapan dari pejabat negara, dan biaya kompensasi kepada masyarakat terdampak.

Teknik pengumpulan data dilakukan dengan penelusuran data online, observasi non partisipan, wawancara, dan studi kepustakaan. Kemudian, penulis menggunakan teknik analisis framing model Pan dan Kosicki untuk mengolah dan menganalisis data yakni sejumlah konten berita mengenai blackout listrik 4 Agustus 2019 di Okezone.com yang sesuai dengan kriteria pemilihan berita.

\section{Hasil Temuan dan Diskusi}

Tabel 1. Pemberitaan Blackout Listrik 4 Agustus 2019 di Okezone.com

\begin{tabular}{|c|c|}
\hline Hari, Tanggal & Judul Berita \\
\hline 1. Minggu, 4 Agustus 2019 & $\begin{array}{l}\text { Mati Listrik Serentak, Plt Bos PLN } \\
\text { Minta Pelanggan Ikhlas }\end{array}$ \\
\hline Senin, 5 Agustus 2019 & $\begin{array}{l}\text { Jokowi Marah dan Langsung Pergi } \\
\text { Usai Dengar Penjelasan Plt Dirut } \\
\text { PLN }\end{array}$ \\
\hline Selasa, 6 Agust & $\begin{array}{l}\text { DKI, Jabar hingga Sebagian Jateng } \\
\text { Blackout, Manajemen PLN } \\
\text { Diminta Taubat Nasuha }\end{array}$ \\
\hline 4. $\quad$ Selasa, 6 Agustus 2019 & $\begin{array}{l}\text { Imbas Mati Listrik, Gaji Pegawai } \\
\text { PLN Dipotong }\end{array}$ \\
\hline Rabu, 7 Agustus 2019 & $\begin{array}{l}\text { Mati Listrik Massal, Fadli Zon: } \\
\text { Jangan Kriminalisasi Pohon } \\
\text { Sengon! }\end{array}$ \\
\hline
\end{tabular}

Sumber: Dokumentasi Peneliti (2019)

Berita pertama secara keseluruhan berisi tentang informasi terkait upaya pemulihan yang dilakukan oleh PLN. Namun, Okezone.com menunjukkan bahwa hal utama yang paling penting dan mendesak diketahui pembaca adalah pernyataan bos PLN yang meminta pelanggan terkena dampak mati listrik serentak untuk ikhlas. Hal tersebut disampaikan pada bagian judul dan ide pertama dalam lead dengan tingkat kemenonjolan yang tinggi yang menunjukkan kecenderungan berita. Okezone.com juga menyampaikan informasi perkiraan waktu listrik di beberapa wilayah bisa kembali pulih sebagai hasil dari upaya yang dilakukan PLN. Namun, informasi penting tersebut ditampilkan di bagian akhir yakni di halaman kedua berita, sehingga terkesan kurang menonjol. 
Lavenia, Lusia Savitri Setyo Utami: Pemberitaan Kasus PT PLN (Persero) di Media Siber dan Penerapan Kode Etik Jurnalistik (Analisis Framing Pemberitaan Blackout Listrik 4 Agustus 2019 di Okezone.Com)

Kemudian, berita kedua menunjukkan Okezone.com menanamkan fakta dalam benak pembaca bahwa penjelasan Plt Dirut PLN terkait penyebab pemadaman listrik secara serentak membuat pemimpin setingkat presiden menjadi marah. Sudut pandang yang ditonjolkan adalah ketidakpuasan Jokowi terhadap keterangan dari bos PLN dan membuat presiden marah. Sementara itu, keterangan tentang penyebab padamnya listrik yang dijelaskan oleh Sripeni menjadi informasi sekunder dan diberikan porsi sangat kecil serta tanpa disertai pengutipan langsung dalam laporan berita tersebut.

Pada berita ketiga, Okezone.com mengkonstruksikan kasus blackout yang mengandung unsur keberpihakan yakni kontra terhadap manajemen dan pengelolaan PLN. Sudut pandang yang ditonjolkan adalah kelalaian dari manajemen dan pengelolaan PLN terhadap kejadian darurat seperti blackout. Sementara itu, dalam berita ini tidak menyertai tanggapan dari PLN terhadap opini yang dilayangkan kepada pihaknya.

Berita keempat cenderung menonjolkan sudut pandang pemotongan gaji pegawai PLN untuk melunasi biaya kompensasi akibat mati listrik. Kemudian, Okezone.com menerangkan alasan PLN mengurangi upah seluruh pegawainya di bagian akhir berita. Okezone.com mengindikasikan kepada pembaca bahwa informasi terpenting adalah PLN potong gaji pegawainya, sedangkan alasan PLN melakukan hal tersebut dianggap kurang penting.

Kemudian, berita kelima menunjukkan bahwa Okezone.com mengkonstruksikan kasus mati listrik massal yang mengandung unsur keberpihakan yakni kontra terhadap penjelasan PLN mengenai pohon sengon menyebabkan insiden blackout. Sudut pandang yang ditonjolkan adalah Okezone.com melalui narasumber melihat hal tersebut sebagai penjelasan kabar bohong dengan kriminalisasi terhadap pohon sengon. Sementara itu, dalam berita ini tidak menyertai tanggapan dari pihak PLN terhadap opini tersebut.

Setelah penulis melakukan analisis framing pada berita-berita blackout listrik 4 Agustus 2019 di Okezone.com tersebut, kemudian penulis mengkajinya dengan Kode Etik Jurnalistik (KEJ) pasal 1 sampai dengan pasal 4. Setelah mengkaji kelima berita tersebut, penulis menemukan tiga berita yang terindikasi tidak menaati aturanaturan dalam KEJ terkait.

Berita dengan headline "DKI, Jabar hingga Sebagian Jateng Blackout, Manajemen PLN Diminta Taubat Nasuha", terindikasi mengabaikan aturan KEJ pasal 3 tentang menguji informasi. Dalam berita ini memuat informasi berdasarkan pernyataan dari Anggota Komisi VII DPR RI Maman Abdurrahman, sebagai berikut: Dia mengatakan, sebetulnya masalah yang hampir serupa bukan hanya di Jabotabek saja. Tapi di seluruh Indonesia. Namun, setelah penulis melakukan penelusuran data online untuk membuktikan kebenaran informasi tersebut, hasil menunjukkan pernyataan Maman bertentangan dengan fakta. Berdasarkan berita-berita di situs CNNIndonesia.com, Detik.com, dan Kompas.com menerangkan bahwa peristiwa blackout listrik pernah terjadi pada tahun 1997, 2002, 2005, 2018, dan 2019. Namun, peristiwa tersebut sebagian besar terjadi di pulau Jawa dan Bali, bukan di seluruh Indonesia. Hal ini menunjukkan bahwa berita Okezone.com tersebut terindikasi mengabaikan kaidah KEJ pasal 3 karena tidak memeriksa kembali tentang kebenaran informasi yang disampaikan oleh narasumber Maman.

Kemudian, berita bertajuk "Imbas Mati Listrik, Gaji Pegawai PLN Dipotong", terindikasi mengabaikan dua kaidah KEJ. Pertama, judul tidak sesuai dengan isi berita atau sering disebut clickbait. Pada judul berita tersebut tidak disertai kata "akan", sehingga terkesan pemotongan gaji tersebut sudah terjadi. Padahal, secara 
objektif dalam isi berita menerangkan bahwa PLN akan memotong gaji pegawainya, berarti hal tersebut belum terjadi. Hal ini menunjukkan judul berita ini tidak akurat sehingga terindikasi mengabaikan asas KEJ pasal 1 yakni menghasilkan berita yang akurat. Kedua, dalam berita ini, Okezone.com menampilkan foto saat pertemuan direksi PLN dengan Komisi VII DPR. Namun, penyiaran gambar tersebut tidak dilengkapi dengan keterangan tentang sumber foto. Hal ini menunjukkan berita Okezone.com tersebut terindikasi mengabaikan kaidah KEJ pasal 2 tentang pemuatan gambar atau foto harus disertai keterangan sumbernya.

Kemudian, berita berjudul "Mati Listrik Massal, Fadli Zon: Jangan Kriminalisasi Pohon Sengon!", terindikasi mengabaikan dua aturan dalam KEJ. Pertama, berita ini menyiarkan tentang opini berupa kritik dari Fadli Zon kepada pihak PLN. Namun, Okezone.com hanya mewawancarai Fadli dan tidak mewawancarai pihak PLN untuk memberikan tanggapan, komentar, klarifikasi, atau bantahan terhadap opini Fadli. Hal ini menunjukkan berita tersebut hanya memuat suara atau keterangan dari satu pihak yakni Fadli. Dengan begitu, berita ini terindikasi mengabaikan KEJ pasal 1 tentang prinsip berimbang karena tidak memberikan kesempatan setara kepada semua pihak. Kedua, dalam tubuh berita ini menampilkan sebuah foto tiang listrik. Namun, gambar tersebut tidak disertai keterangan sumber. Dengan begitu, berita ini juga terindikasi mengabaikan kaidah KEJ pasal 2.

Menurut Anggota Dewan Pers Asep Setiawan, saat ini praktik jurnalistik oleh media siber di Indonesia masih banyak yang tidak memperhatikan prinsip-prinsip kode etik jurnalistik dalam pemberitaannya. Setiap tahun Dewan Pers mendapatkan lebih dari 300 kasus aduan per tahun terkait pelanggaran kode etik jurnalistik. Di samping pemberitaan di media siber yang sangat cepat, Asep mengatakan perusahaan pers dan jurnalisnya tetap harus mengutamakan penerapan kaidah-kaidah kode etik jurnalistik dalam menyiarkan berita kepada khalayak.

Setelah melakukan analisis framing pada pemberitaan di media siber Okezone.com, penulis menemukan bahwa sebagian besar setiap berita dituliskan hanya berdasarkan pernyataan dari satu pihak. Lalu, jika terdapat informasi lanjutan yang disampaikan oleh pihak terlibat lainnya akan diperbarui pada berita selanjutnya dengan headline menggunakan kata kunci yang berkaitan. Hal ini menunjukkan bahwa penerapan prinsip cover both side pada media siber mempunyai perbedaan dibandingkan dengan pemberitaan di media cetak seperti surat kabar.

Dengan menggunakan sarana internet, media siber mengandalkan kecepatan yang sekaligus menjadi karakter khusus dalam menyajikan beragam berita kepada khalayak. Maka ditetapkan Pedoman Pemberitaan Media Siber oleh Dewan Pers berdasarkan Undang-Undang Republik Indonesia Nomor 40 Tahun 1999 tentang pers dan kode etik jurnalistik yang memberikan aturan khusus sesuai dengan sifat pemberitaan media siber agar dikelola secara profesional (Dewan Pers, 2012).

Pemberitaan di media siber seolah tak asing dengan penggunaan headline yang bombastis sebagai daya tarik untuk mendatangkan pembaca sebanyak mungkin. Uniknya, strategi tersebut berhasil sebab sering kali pembaca membuka artikel-artikel karena khalayak tergoda dengan headline yang sensasional, meski tak jarang ditemukan ketidaksesuaian informasi yang diuraikan pada tubuh berita. Selain itu, alur cerita dalam struktur berita di media siber cenderung berbeda. Penyusunan judul, lead, latar informasi, kutipan, pernyataan, dan penutup berita tidak selalu dituliskan secara berurutan. Hal ini dipengaruhi oleh gaya penulisan dan perspektif masing-masing jurnalis dalam memaknai dan mengisahkan suatu peristiwa atau isu kepada khalayak. 
Lavenia, Lusia Savitri Setyo Utami: Pemberitaan Kasus PT PLN (Persero) di Media Siber dan Penerapan Kode Etik Jurnalistik (Analisis Framing Pemberitaan Blackout Listrik 4 Agustus 2019 di Okezone.Com)

Dengan demikian, hal-hal tersebut membuktikan bahwa karakteristik dan tren pemberitaan media siber sangat memengaruhi proses hingga hasil pembingkaian berita yang disampaikan oleh jurnalis kepada khalayak pembaca. Selain itu, sebenarnya sebuah berita dituliskan secara objektif sekaligus subjektif. Hal ini dikarenakan jurnalis memberitakan berdasarkan fakta secara objektif, namun juga bersifat subjektif dalam memilih narasumber yang akan diwawancarai, sudut pandang yang akan ditonjolkan, pernyataan narasumber yang akan dikutip, dan lainnya. Dengan demikian, dalam penelitian ini tergambar bahwa tidak ada media yang benar-benar netral dan objektif dalam menyeleksi fakta dan menulis berita.

\section{Simpulan}

Berdasarkan hasil temuan dan diskusi, kesimpulan dari penelitian ini adalah secara keseluruhan Okezone.com membingkai pemberitaan tentang blackout listrik 4 Agustus 2019 dengan menerapkan prinsip cover both side yang disajikan dalam artikel-artikel berbeda karena karakteristik pemberitaan di media siber yang sangat cepat. Kemudian, dalam mengemas isu-isu kontroversial, beberapa pemberitaan Okezone.com menonjolkan sudut pandang yang cenderung menyudutkan pihak PLN seperti manajemen dan pengelolaan yang sangat bobrok dan tidak memiliki upaya antisipasi terhadap kejadian blackout. Oleh karena itu, penulis merekomendasi agar jurnalis menerapkan asas praduga tak bersalah dengan tidak menyudutkan suatu pihak dalam pemberitaannya. Kemudian, Okezone.com masih cukup baik dalam menerapkan kaidah-kaidah kode etik jurnalistik pasal 1 hingga pasal 4. Setelah penulis menganalisis dan mengkaji pemberitaan blackout listrik 4 Agustus 2019, hanya prinsip penulisan keterangan mengenai sumber foto yang beberapa terindikasi mengabaikan KEJ pasal 2. Dengan begitu, penulis menyarankan agar perusahaan pers lebih menekankan penerapan kode etik jurnalistik kepada jurnalisnya saat meliput dan menulis berita.

\section{Ucapan Terima Kasih}

Ucapan terima kasih diberikan kepada Allah SWT, Fakultas Ilmu Komunikasi Universitas Tarumanagara, Redaktur Pelaksana Okezone.com Rani Hardjanti dan Anggota Dewan Pers Asep Setiawan selaku narasumber, Sekretaris Redaksi Okezone.com Evi Yulianti dan pihak Sekretariat Dewan Pers Wawan Agus Prasetyo.

\section{Daftar Pustaka}

Bungin, M. Burhan. (2010). Penelitian Kualitatif: Komunikasi, Ekonomi, Kebijakan Publik Dan Ilmu Sosial Lainnya. Jakarta: Kencana Prenada Media Group.

Dewan Pers (2008). Kode Etik Jurnalistik. Agustus 23, 2019. https://dewanpers.or.id/kebijakan/peraturan

Dewan Pers (2012). Pedoman Pemberitaan Media Siber. Januari 7, 2020. https://dewanpers.or.id/kebijakan/pedoman

Eriyanto. (2011). Analisis Framing: Konstruksi, Ideologi, dan Politik Media. Yogyakarta: LKiS Yogyakarta.

Hartomo, Giri. (2019, Agustus 5). Jokowi Marah dan Langsung Pergi Usai Dengar Penjelasan Plt Dirut PLN. Oktober 24, 2019. Okezone database. 
https://economy.okezone.com/read/2019/08/05/320/2087769/jokowi-marahdan-langsung-pergi-usai-dengar-penjelasan-plt-dirut-pln

Hartomo, Giri. (2019, Agustus 6). Imbas Mati Listrik, Gaji Pegawai PLN Dipotong. Oktober 2019. Okezone database. https://economy.okezone.com/read/2019/08/06/320/2088480/imbas-matilistrik-gaji-pegawai-pln-dipotong

Hasan, Reynaldi. (2019, Agustus 5). Mati Lampu, Warga Ketakutan hingga Polisi Jaga Objek Vital. Agustus 23, 2019. Liputan6 database. https://www.liputan6.com/news/read/4030085/mati-lampu-warga-ketakutanhingga-polisi-jaga-objek-vital

Kusumadewi, Etika Widya. Dan Rusdi, Farid. (2016). Analisis Framing Pemberitaan Kisruh Partai Golkar Pasca Keputusan Menkumham Dalam Program Dialog Primetime News Metro TV dan Kabar Petang TV One. Jurnal Komunikasi, 8(2), 189-206. Terarsip di https://journal.untar.ac.id/index.php/komunikasi/article/view/68/152

Muhtadi, Asep Saeful. (2016). Pengantar Ilmu Jurnalistik. Bandung: Simbiosa Rekatama Media.

Muntinanto, Wahyu. (2019, Agustus 4). Mati Listrik Serentak, Plt Bos PLN Minta Pelanggan Ikhlas. Oktober 24, 2019. Okezone database. https://economy.okezone.com/read/2019/08/04/320/2087563/mati-listrikserentak-plt-bos-pln-minta-pelanggan-ikhlas

Musman, Asti., \& Mulyadi, Nadi. (2017). Jurnalisme Dasar: Panduan Praktis Para Jurnalis. Bantul: Komunika.

Putra, Ade. (2019, Agustus 6). DKI, Jabar hingga Sebagian Jateng Blackout, Manajemen PLN Diminta Taubat Nasuha. Oktober 25, 2019. Okezone database. https://economy.okezone.com/read/2019/08/06/320/2088320/dkijabar-hingga-sebagian-jateng-blackout-manajemen-pln-diminta-taubat-nasuha

Rizky, Muhamad. (2019, Agustus 7). Mati Listrik Massal, Fadli Zon: Jangan Kriminalisasi Pohon Sengon!. Oktober 26, 2019. Okezone database. https://megapolitan.okezone.com/read/2019/08/07/338/2088883/mati-listrikmassal-fadli-zon-jangan-kriminalisasi-pohon-sengon

Romli, Asep Syamsul M. (2018). Jurnalistik Online: Panduan Mengelola Media Online. Bandung: Nuansa Cendekia.

Romli, Khomsahrial. (2016). Komunikasi Massa. Jakarta: Grasindo.

Sumadiria, AS Haris. (2011). Jurnalistik Indonesia: Menulis Berita dan Feature. Bandung: Simbiosa Rekatama Media. 